\title{
Diversidad lingüística y educación
}

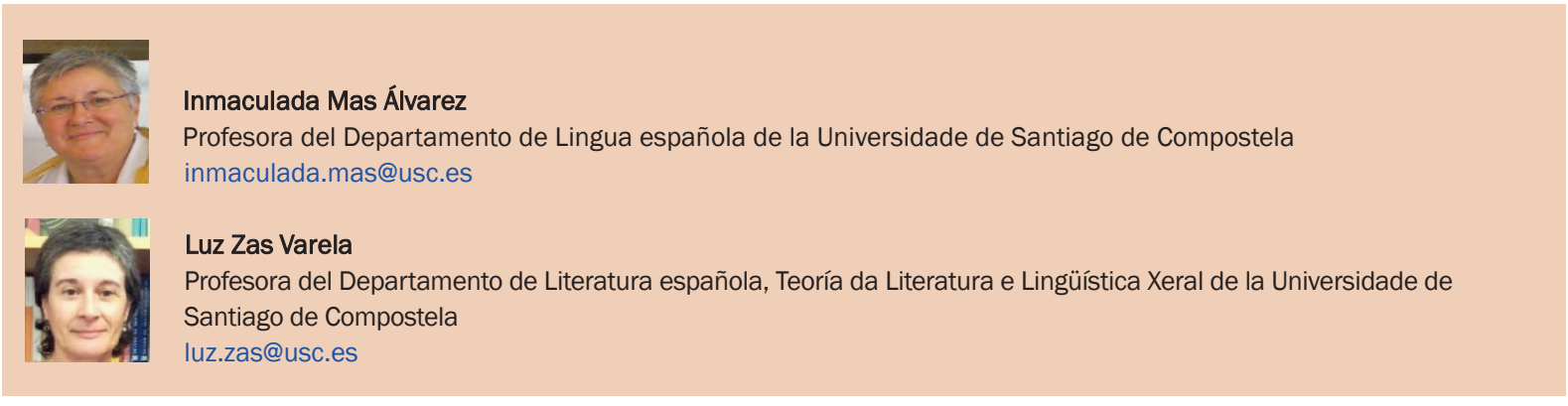

|Fecha de presentación: 17/10/2011 | Aceptación: 23/11/2011 |Publicación: 23/12/2011

\begin{abstract}
Resumen
Presentamos las actividades conjuntas llevadas a cabo en el $2^{\circ}$ curso de formación de maestros (Lengua extranjera) para las asignaturas de Lingüística y Lengua española en la Universidad de Santiago de Compostela. Desde un contexto universitario de adaptación al Espacio Europeo de Educación Superior y teniendo en cuenta que nos encontramos en una comunidad bilingüe, los objetivos comunes principales de nuestras programaciones han sido: contrarrestar la excesiva fragmentación entre las materias lingüísticas, promover la reflexión sobre la toma de conciencia de la diversidad lingüística y cultural, fomentar la aplicación de las TIC y potenciar el trabajo colaborativo.
\end{abstract}

Palabras clave: lingüística aplicada, educación lingüística, diversidad lingüística, plurilingüismo, tratamiento integrado de las lenguas

\section{Resum}

Presentem les activitats conjuntes dutes a terme al $2 n$ curs de formació de mestres (Llengua estrangera) per a les assignatures de Lingüística i Llengua espanyola a la Universitat de Santiago de Compostela. Des d'un context universitari d'adaptació a l'Espai Europeu d'Educació Superior i tenint en compte que ens trobem en una comunitat bilingüe, els objectius comuns principals de las nostras programaciós han estat: contrarestar l'excessiva fragmentació entre les matèries lingüístiques, promoure la reflexió sobre la presa de consciència de la diversitat lingüística i cultural, fomentar l'aplicació de les TIC i potenciar el treball colllaboratiu.

Paraules clau: llingüística aplicada, educació lingüística, diversitat lingüística, plurilingüisme, tractament integrat de les llengües

\begin{abstract}
We introduce the shared activities carried out in the 2nd year of teacher training (Foreign Language Courses) for the subjects Spanish Language and Linguistics at the University of Santiago de Compostela. From a university context of adaptation to the European Higher Education Area (EHEA) and taking into account that we are in a bilingual community, the main objectives of our programs have been: to counter the excessive fragmentation of linguistic materials, to promote reflection on awareness of linguistic and cultural diversity, to promote the application of ICT and to enhance collaborative work.
\end{abstract}

Keywords: Applied Linguistics, Language Education, Linguistic Diversity, Multilingualism, Language Integrated Treatment 


\section{Introducción}

En los últimos años asistimos a un cambio de gran importancia para la docencia de lenguas, que afecta a la mayoría de las comunidades y a las lenguas del alumnado de la educación obligatoria. El efecto migratorio de los últimos tiempos implica que los estudiantes incorporan sus lenguas y sus culturas a los diversos lugares de acogida donde existen otras lenguas. Este hecho tiene una consecuencia muy clara, los centros educativos, de la misma manera que el resto de la sociedad, han dejado de ser monolingües o bilingües para convertirse en centros multilingües y multiculturales.

La institución escolar se presenta, pues, como uno de los ámbitos en los que se constata de manera más notoria desde el comienzo de siglo la creciente diversidad cultural y lingüística de nuestra sociedad. El tratamiento de esta diversidad requiere en la escuela una programación específica, una reinterpretación y readaptación en los planteamientos curriculares de las áreas lingüísticas.

En algunas zonas de Galicia, no resulta tan anecdótico escuchar lenguas como el chino, volof, caboverdiano o árabe. Desde esta perspectiva, ya no es suficiente con definir a las comunidades escolares de Galicia, Cataluña o País Vasco como bilingües. En el ámbito escolar gallego hemos constatado que la presencia de ciertas lenguas en la escuela es relevante desde el punto de vista cuantitativo, éstas son fundamentalmente: árabe, chino, volof, ruso, polaco, rumano, portugués (portugués de Brasil), caboverdiano, quechua, guaraní y el español en sus diversas variedades americanas (de Argentina, Venezuela, Colombia, Perú) ${ }^{1}$.

Teniendo en cuenta esta realidad, se hace necesario diseñar programas de actividades y experiencias didácticas para tratar la diversidad lingüística y considerar de qué modo las lenguas de los estudiantes pueden adquirir cierto interés en los proyectos lingüísticos de centro y en el diseño de los propios materiales curriculares.

En este sentido, adquiere también relevancia la repercusión de esta nueva situación en los programas de formación del profesorado, en especial, y es lo que vamos a tratar en nuestro artículo, en los programas de Lingüística y Lenguas en los diversos Grados de Maestros. Incorporar en el nivel universitario la consideración de la diversidad lingüística y cultural como centro de interés y punto de partida puede aportar argumentos interesantes para una reflexión detenida sobre los prejuicios lingüísticos, en especial cuando se propugna una puesta en valor de lenguas minorizadas.

\section{La dimensión plurilingüe y pluricultural en el contexto europeo}

Como se ha puesto de manifiesto en numerosos documentos, la diversidad lingüística constituye un reto para Europa, en concreto, para el Consejo de Europa. La implantación del Marco común europeo de referencia para las lenguas: aprendizaje, enseñanza y evaluación (MCER), cuyo objetivo es proporcionar unas bases comunes para la enseñanza y aprendizaje de lenguas, ha generado y sigue generando debates interesantes sobre los cambios en el modo de abordar los currículos de las lenguas.

El concepto de competencia plurilingüe y pluricultural, ha desterrado la separación clásica entre el aprendizaje de una lengua nacional y una lengua extranjera, así, leemos en el MCER (Consejo de Europa 2001:31-32):

"[...] la finalidad de la educación en una lengua queda profundamente modificada. Ya no se entiende como el simple logro del "dominio" de una o dos, o incluso de tres lenguas, cada una considerada de forma aislada, con el "hablante nativo ideal" como modelo fundamental. En vez de esto, el objetivo es el desarrollo de un repertorio lingüístico en el que estén implicadas todas las capacidades lingüísticas. Esto supone, naturalmente, que las lenguas que se ofrecen en las instituciones educativas tienen que diversificarse y que a los alumnos debe dárseles la posibilidad de desarrollar una competencia plurilingüe [...]"

Desde esta perspectiva, Mercè Bernaus, siguiendo a Teresa Tinsley (2003), menciona las diferencias entre un modelo tradicional de enseñanza y aprendizaje de lenguas y un nuevo enfoque didáctico. A nuestro modo de ver las características del nuevo modelo, que reproducimos resumidas en la Tabla 1 deben consitituir el punto de partida de cualquier programación innovadora.

No cabe duda de que asumir estos presupuestos tiene una enorme repercusión en la formación del profesorado. La docencia en las clases de lenguas requiere conocimientos en el área de la Lingüística, como los conocimientos necesarios para comparar sistemas lingüísticos diversos, los conocimientos básicos sobre procesos de aprendizaje de las lenguas primeras y segundas o los conocimientos sociolingüísticos para entender las relaciones entre las lenguas y los grupos sociales que las hablan.

Tener en cuenta las diversas lenguas y culturas del alumnado en los centros escolares supone elaborar un proyecto lingüístico de centro que fomente la competencia plurilingüe y pluricultural; supone facilitar la presencia de las diversas lenguas y culturas del alumnado, mediante proyectos y actividades específicas (Grupo Eleuterio Quintanilla 2006, Autores 2009).

En este sentido, el Consejo de Europa destaca que el rico patrimonio de las lenguas y las culturas es un recurso que se debe proteger y desarrollar. El MCER hace una clara defensa del enfoque plurilingüe y pluricultural en la enseñanza de las lenguas al recoger entre sus principios rectores el siguiente (Consejo de Europa 2001, 2):

"Que el rico patrimonio de las distintas lenguas y culturas de Europa constituye un recurso común muy valioso que hay que proteger y desarrollar, y que se hace necesario un gran esfuerzo educativo con el fin de que esa diversidad deje de ser un obstáculo para la comunicación y se convierta en una fuente de enriquecimiento y comprensión mutuos."

\section{La dimensión plurilingüe y pluricultural en la formación de docentes de lenguas}

En la actualidad es necesario incorporar la dimensión plurilingüe y pluricultural a la formación inicial de futuros maestros en general y, de manera más patente, a la de futuros docentes de lenguas, tanto de las autóctonas como de las extranjeras. A lo largo de la primera década de este siglo, las distintas instancias implicadas en la formación del profesorado se han

${ }^{1}$ Las lenguas y variedades aquí destacadas se han mostrado como relevantes en los datos obtenidos a partir de un cuestionario sobre la presencia de lenguas diferentes del gallego y castellano entre los escolares de Galicia. El diseño, implementación y evaluación de los datos se han llevado a cabo en el seno del proyecto financiado por la Xunta de Galicia Plurilingüismo e conciencia lingüística. Recursos educativos para o desenvolvemento da competencia inter.cultural (INCITE08PXIB400065PR) 


\begin{tabular}{|l|l|}
\hline Modelo tradicional & Nuevo modelo \\
\hline $\begin{array}{l}\text { Enfoque en la nación-estado y en la lengua de la nación como } \\
\text { fuente de identidad }\end{array}$ & Énfasis en la ciudadanía europea y en la diversidad lingüística \\
\hline El plurilingüismo es un problema para la sociedad & El plurilingüismo enriquece a la sociedad \\
\hline $\begin{array}{l}\text { El bilingüismo y la procedencia de una cultura diferente son } \\
\text { silenciados }\end{array}$ & $\begin{array}{l}\text { El bilingüismo y la procedencia de una cultura diferente son bien } \\
\text { acogidos }\end{array}$ \\
\hline $\begin{array}{l}\text { La educación bilingüe en la escuela se ve como un problema. } \\
\text { Los niños deben ser instruidos en la lengua nacional para es- } \\
\text { tudiar otras lenguas posteriormente }\end{array}$ & $\begin{array}{l}\text { La educación bilingüe o plurilingüe se apoya porque puede favorecer } \\
\text { el aprendizaje de lenguas diversas paralelamentey al mismo tiempo }\end{array}$ \\
\hline Los hablantes de otras lenguas son "foráneos" & Los hablantes de otras lenguas forman parte de nuestra comunidad \\
\hline Aprender otras lenguas es difícil & Aprender otras lenguas es normal \\
\hline $\begin{array}{l}\text { Adquirir un nivel de lengua casi como la de un nativo es el ob- } \\
\text { jetivo final }\end{array}$ & $\begin{array}{l}\text { Se valoran los niveles de competencia comunicativa más básicos } \\
\text { en diversas lenguas, que se irán adquiriendo a lo largo de la vida }\end{array}$ \\
\hline $\begin{array}{l}\text { La enseñanza/aprendizaje se centra casi exclusivamente en ob- } \\
\text { jetivos lingüísticos. La cultura no se contempla o se presenta } \\
\text { de forma estereotipada }\end{array}$ & $\begin{array}{l}\text { La enseñanza/aprendizaje contiene elementos culturales a fin } \\
\text { de concienciar al alumnado respecto a la pluriculturalidad y a } \\
\text { valorar y respetar otras lenguas, sus hablantes y otras culturas }\end{array}$ \\
\hline $\begin{array}{l}\text { La enseñanza/aprendizaje se centra en una sola lengua. No se } \\
\text { pueden aprender a la vez dos o más lenguas }\end{array}$ & $\begin{array}{l}\text { La enseñanza/aprendizaje de lenguas establece vínculos entre va- } \\
\text { rias lenguas y entre lenguas muy diversas con el fin de que el alum- } \\
\text { nado adquiera una conciencia lingüística (language awareness) }\end{array}$ \\
\hline $\begin{array}{l}\text { El aprendizaje de lenguas tiende a ser elitista y problemático } \\
\text { para la mayoría }\end{array}$ & $\begin{array}{l}\text { El aprendizaje de la lengua está al alcance de la mayoría. Lo cual } \\
\text { ha de facilitar la comunicación entre los que vivimos en socie- } \\
\text { dades cada vez más plurilingües y pluriculturales }\end{array}$ \\
\hline
\end{tabular}

Tabla 1. Características del nuevo enfoque frente al modelo tradicional de enseñanza y aprendizaje de lenguas (a partir de Bernaus 2004: 4-5)

hecho eco de la perspectiva presentada someramente en el apartado anterior, reclamando su reflejo en la formación de maestros. Véanse, por ejemplo, a este respecto, las reflexiones y propuestas de profesores del área de Didáctica de la Lengua y la Literatura, reunidos en 2005 en un encuentro sobre el presente y futuro del área; entre ellas destacamos la que se refiere explícitamente a la formación del profesorado (AA VV 2005):

"De acuerdo con las líneas marcadas por el Consejo de Europa en su documento titulado Guía para la elaboración de las Políticas lingüísticas europeas, de la División de las Políticas Lingüísticas, los participantes coinciden en que la formación de profesores requiere una reconversión profesional para una Educación plurilingüe como orientación actual de la Educación, que permita responder a la complejidad de la identidad cultural y de la comunicación intercultural. Estas problemáticas actuales de nuestro contexto social y cultural constituyen, a su vez, los dos pilares en los que debe basarse una enseñanza lingüística y literaria de calidad”.

Así pues, pensamos que en estos momentos es ineludible proporcionar a los futuros docentes de lenguas la oportunidad de formarse en educación plurilingüe e intercultural, a la vez que se mantiene una formación sólida en lengua. Como afirma Brotons Rico (2006):

"Toda esta complejidad educativa e idiomática debe estar presente en la formación de los futuros maestros, maestras, profesoras y profesores de los niveles obligatorios, preobligatorios y postobligatorios del Sistema Educativo. No se trata sólo de tener buenos enseñantes de castellano, catalán/valenciano, eusquera, gallego, inglés o francés. Los objetivos educativos deben ser más amplios y ambiciosos en este terreno. Todas y todos los maestros deben tener una formación para la educación plurilingüe y multicultural - también intercultural-que permita abordar esa futura sociedad, ya presente, que tendrá en muchos colegios unos porcentajes entre el $10 \%$ y el $60 \%$ que hablarán lenguas distintas al castellano y/o la de la comunidad autónoma respectiva”.

En el mismo sentido se manifestaba la experta canadiense en educación lingüística en entornos multilingües, Elisabeth Coelho, en una entrevista concedida durante su participación en Barcelona en el ciclo de CaixaFórum "Los retos educativos del siglo XXI”. En su opinión, los profesores carecen de la formación y de la ayuda adecuadas para afrontar los retos y oportunidades del multilingüismo y el multiculturalismo en los centros escolares. Coelho señaló que "no es justo graduar a nuevos profesores sin las habilidades que necesitan en este nuevo tipo de contexto. No es justo para los maestros, que no tienen la culpa de no tenerlas, y no es justo para los alumnos" (Coelho 2008)².

\section{Nuestro proyecto de actividades ${ }^{3}$}

Como profesoras de áreas lingüísticas hemos desarrollado a lo largo de los cursos más recientes un conjunto de actividades compartidas que ha pretendido tener muy presente estas

\footnotetext{
2 Véase también el artículo del que Coelho es coautora en este mismo monográfico.

${ }^{3}$ Destacamos aquí tan solo tres actividades conjuntas, pero estas comprendieron diversas tareas conectadas a su vez con el desarrollo independiente del trabajo en cada asignatura. Entiéndase que nos referimos, pues, a tres hitos ya que supusieron tres motores en torno a los cuales cada profesora organizó e impulsó el trabajo expositivo y de discusión en el aula. Una primera versión del texto de este apartado 4 . lo presentamos en forma de comunicación, con el título Formación lingüística para futuros maestros de lenguas extranjeras, al XI Congreso Internacional de la SEDLL, que tuvo lugar en Jaén entre los días 1 y 3 de diciembre de 2010, bajo el lema "Enseñanza y aprendizaje de lenguas extranjeras con enfoque competencial". Agradecemos desde aquí los comentarios y sugerencias que recibimos en el transcurso del Congreso a propósito de nuestro trabajo.
} 
demandas reclamadas por la realidad escolar. En nuestro caso, hemos contado, además, con un alumnado especialmente sensible a la convivencia de lenguas, ya que cursa una especialidad de lengua extranjera -francés o, en su mayoría, inglés-y, en no pocos casos, está compuesto de personas plurilingües, cuyos padres, madres o abuelos fueron inmigrantes gallegos en países de habla inglesa, francesa o alemana.

Desde dos asignaturas obligatorias del segundo cuatrimestre de $2^{\circ}$ curso de la titulación de Maestro en Lengua extranjera, Lingüistica y Lengua y Literatura españolas, hemos adoptado como referencia aspectos comunes de sendos programas para llevar a cabo un conjunto de experiencias didácticas centradas en la toma de conciencia de la diversidad lingüística y cultural y el fomento de actitudes positivas hacia ella. Los intereses comunes que han guiado la programación compartida son los siguientes:

- Contrarrestar la excesiva fragmentación entre las asignaturas de corte lingüístico

- Fomentar una actitud crítica ante los recursos disponibles y su aplicabilidad en la didáctica de lenguas

- Enfocar las actividades poniendo en primer término el interés por la variación lingüística en todas sus formas, adoptando una actitud libre de prejuicios

- Propiciar la reflexión metalingüística y metacognitiva.

- Favorecer el empleo de las TIC, tanto en aspectos metodológicos de la organización del curso como en las tareas grupales ${ }^{4}$

- Fomentar el trabajo colaborativo, de manera que sirva también de referencia o modelo de cara al futuro profesional de los estudiantes

Nuestra pretensión ha sido, pues, la de programar actividades para el ámbito universitario que se planteen como objetivos los que consideramos ya prioritarios para la enseñanza de lenguas en los niveles de escolaridad obligatoria. Para nosotras ha sido fundamental desarrollar una labor docente que pueda constituir en sí misma un modelo de cambio en objetivos y metodología, dando prioridad a la participación real de alumnas y alumnos en el aula y al trabajo colaborativo enfocado al desarrollo de tareas auténticas.

Desde este enfoque, entendemos el aula como un escenario comunicativo donde se comparten saberes democráticos que nos permiten aprender a convivir en la diversidad lingüística y cultural. Las tareas y actividades realizadas están orientadas a mostrar el valor igualitario de las diferentes lenguas y variedades con independencia de su ámbito geográfico y su estatuto sociopolítico, ya que todas ellas sirven como instrumento de comunicación e identidad de las comunidades de habla. Como indica Lomas (2011: 16-17), conviene tratar en las aulas las cuestiones relativas a los prejuicios de valor sobre las lenguas, pues "no son ajenas a esos prejuicios, a esas supersticiones y a esas jerarquías, agitadas a menudo por una trifulca política donde algunos agitan con aires apocalípticos la falacia de la supremacía de unas lenguas y de la subordinación de otras".

La primera de las actividades propuestas, que sirvió como punto de partida para el desarrollo del trabajo colaborativo fuera y dentro del aula a lo largo del cuatrimestre, fue un debate sobre la situación de las lenguas minorizadas a partir del visionado del documental Última palabra, realizado en 2001 por Grau Serra Espriu. El documental trata sobre la desaparición paulatina de lenguas indígenas en el México del siglo XXI, con la consiguiente pérdida cultural, de tradiciones y de historia. Se recogen testimonios de comunidades cuyas lenguas están en peligro de extinción, ya que en el momento del rodaje conservaban no más de cinco hablantes, todos ellos ancianos.

El interés del documental no reside solo en mostrar los grupos étnicos con idiomas minoritarios -el popoluca, el mayo, el lacandón-, sino también en el hecho de ser portador del sentimiento de personas que ven cómo toda su cultura y civilización desaparecerá con ellos o con sus hijos. Cuando estas personas mueran, se extinguirán su lengua y su cultura. Como actividad de sensibilización que invita al debate y la reflexión sobre vida y muerte de las lenguas, este documental se ha revelado un recurso insustituible.

El segundo hito de la programación fue la visita - financiada por la Facultad de Ciencias de la Educación como prácticas de campo- al Verbum, museo interactivo sobre el lenguaje y la comunicación. El Verbum o Casa das Palabras es un museo dedicado a todos los aspectos relacionados con el fenómeno de la comunicación. Está situado en Vigo, en la Playa de Samil, y cumplió el 25 de abril de 2010 siete años dedicados a la cultura, divulgación y el entretenimiento, basándose en la participación de los visitantes a través de las propuestas interactivas que ofrece.

La sección permanente constituyó el objetivo prioritario de nuestra visita, ya que la consideramos un recurso muy aprovechable, de hecho está funcionando así cada curso, para visitas de escolares de todas las edades; por ello, consideramos que debe prestar atención especializada a los aspectos didácticos y a la creación de materiales. Por otra parte, pensamos que su revisión y actualización son necesarias, dado que trata de un ámbito, el de la comunicación, en constante desarrollo y cambio. En algunas noticias publicadas a raíz de la repercusión del séptimo aniversario se incidía en este mismo hecho:

"El núcleo del Verbum, su muestra permanente, son 29 cubos interactivos correspondientes a las letras del alfabeto, en los que se desarrollan diferentes temáticas alrededor de la comunicación humana. En principio, la intención era renovarlos cada año, pero desde su apertura solamente se han cambiado dos. ["El Verbum llega a los 7 años de vida con una media de cien visitas al día", La Voz de Galicia, 12.04.2010]

[Se revisará] la exposición permanente, en formato de cubos. "Se corregirán los fallos de enfoque, morfología y sintaxis evidentes, pero no su apariencia formal porque resultaría demasiado costoso". Lo que se descarta, por irrealizable, es la pretensión de modificar sus contenidos anualmente, un requisito anunciado al inicio y nunca cumplido. ["El Verbum cumple siete años a la espera de un plan”, El País, 25.04.2010]”

Además, nos parece interesante que desde el ámbito universitario se produzcan acercamientos críticos a los museos

${ }^{4}$ Para la asignatura de Lingüística se empleó el Aula Virtual de la Universidad de Santiago de Compostela y para la Lengua española el lugar virtual de referencia del área fue una wiki abierta y mantenida por la profesora (con la tecnología de wikispaces). 
en su dedicación a la divulgación científica; tenemos en cuenta el compromiso de la universidad con la sociedad y la transferencia de conocimiento, así como la necesidad de una proyección hacia el marco social a través de la extensión cultural.

Los objetivos concretos que guiaron las actividades conectadas con la visita a la Casa de las palabras fueron los siguientes:

- Conocer el trabajo de divulgación de un museo cercano de contenido original directamente relacionado con estas asignaturas y fomentar el espíritu crítico respecto de los contenidos y la presentación interactiva

- Reflexionar sobre la utilidad didáctica de la exposición permanente y de las visitas guiadas en relación con los contenidos propuestos

- Fomentar el trabajo en grupo, tanto en el aspecto colaborativo como en el de uso de las TIC

- Ofrecer una actividad coordinada entre dos materias relacionadas con el lenguaje y las lenguas

- Llevar a cabo un conjunto de actividades auténticas

- Dar cabida, a través de una actividad académica, a la convivencia fuera del aula y la faceta lúdica asociada a una salida

En primer lugar, como trabajo previo a la visita, los estudiantes tenían que familiarizarse con el museo a través de su web - permite un paseo virtual y conocer los contenidos de la exposición permanente- y elegir un aspecto de los tratados en alguno de los 29 cubos (por ejemplo, "la comunicación y la tecnología" o "dime como hablas...")5. Una vez elegido este aspecto, se les animaba a reflexionar sobre lo que, a su parecer, sería interesante mostrar en un museo que se dice interactivo en relación con el aspecto elegido. Más tarde, ya en la visita real, se contrastaba con la reflexión inicial, teniendo en cuenta los objetivos del museo y sus destinatarios. Como producto final cada grupo de estudiantes escribió una breve carta dirigida a la Dirección del museo, con sus impresiones y sugerencias para mejorar el cubo elegido.

Paralelamente, se había llevado a cabo un trabajo en grupo sobre una lengua del mundo, reuniendo información sobre su tipología, familia lingüística y situación social, con especial atención a la planificación en el sistema educativo. El producto final en este caso consistía en una propuesta de actividad o actividades concretas para trabajar en la escuela -o en un museo interactivo- sobre esa lengua seleccionada (véanse algunos ejemplos de propuestas más abajo). Cada grupo llevó a cabo una exposición de su trabajo y las aplicaciones ideadas.

La tercera y última de las actividades de la programación fue un seminario sobre el Portfolio europeo de las lenguas con Daniel Cassany como profesor invitado ${ }^{6}$. Comenzamos con una conferencia sobre "La diversidad lingüística en el aula”, en la que el profesor Cassany expuso algunos principios del trabajo en el aula con el PEL, incluyendo ejemplos reales de aplicación (Cassany 2006). El desarrollo de un taller de tres horas de trabajo en grupo a partir del Test sobre plurilingüismo, fue la guinda con que cerramos el curso. A pesar de que el recorrido trazado antes del taller había propiciado el debate y la reflexión sobre la gestión de la diversidad lingüística y cultural en el aula, la discusión en grupo a propósito de los tópicos sobre el aprendizaje de lenguas y las actitudes hacia la diversidad de lenguas y variedades que el Test pone sobre el tapete supuso para muchos la oportunidad de clarificar conceptos y asentar argumentos.

Hemos mostrado el proceso seguido para tratar e investigar sobre un tema, el de la diversidad lingüística y cultural, y cómo surgen, mediante tareas y actividades diversificadas, diferentes subtemas que permiten comprender el alcance de los aspectos tratados. Además, no solo el aula se convierte en espacio discursivo y de reflexión educativa, sino que la educación se abre a espacios más amplios, como por ejemplo el de un museo.

\section{Actividades realizadas por los estudiantes. Algu- nos ejemplos}

A continuación comentamos brevemente algunas de las actividades que han sido realizadas por los diferentes grupos de estudiantes ${ }^{7}$. Recordemos que se trataba de llevar a cabo una tarea de investigación en cada grupo de trabajo. La investigación realizada giró en torno a las siguientes lenguas: gaélico, sardo, bretón, maorí, volof, tagalo, carelio, amárico, maya y mapuche.

Cada grupo de trabajo debía investigar aspectos sociolingüísticos sobre cada una de las lenguas seleccionadas. Debían fijarse, sobre todo, en las cuestiones que se refieren al estatuto de las lenguas en el ámbito educativo y desarrollar una propuesta creativa que les permitiera crear materiales, en el rol de futuros docentes, destinados a alumnos de Educación Primaria, con el objetivo de dar a conocer cada una de las lenguas elegidas.

El procedimiento metodológico para llevar a cabo las diferentes actividades fue de tipo colaborativo. Cada miembro del grupo asumió una responsabilidad concreta: la búsqueda de información sobre un aspecto, selección de información, redacción de un texto y exposición al resto de los miembros del grupo. A continuación, cada grupo elaboró un informe conjunto en el que sintetizó los aspectos investigados para presentarlos finalmente al resto de la clase.

Exponemos en lo que sigue algunas de las ideas desarrolladas, con intención de que constituyan una pequeña muestra representativa del conjunto de trabajos llevados a cabo. Las hemos seleccionado por su carácter creativo y porque, en unos casos en mayor medida que en otros, los estudiantes pusieron en práctica algunas de las lecciones de la asignatura de Nuevas tecnologías, cursada en el cuatrimestre anterior.

La propuesta sobre el amárico planteaba una actividad para estudiantes de Educación Primaria consistente en realizar un puzle de cinco piezas con el perfil de Etiopía. Una vez encajadas las piezas correctamente se forma el nombre del país, escrito en el alfabeto del amárico. Para descifrarlo los niños tendrían que utilizar un silabario que estaría ex-

${ }^{5}$ Enlace al sitio del museo: http://www.verbum.vigo.org/es/index_es.php

${ }^{6}$ La presencia del profesor Cassany fue posible gracias a la financiación conjunta de la visita por parte del Vicerrectorado de Investigación e Innovación, el Departamento de Lengua española y el Decanato de la Facultad de Ciencias de la Educación, de la Universidad de Santiago de Compostela.

${ }^{7}$ El alumnado que participó en estas actividades fue la promoción que cursaba en 2009-2010 $2^{\circ}$ de la Diplomatura de Maestro en la especialidad de Mestre en Lingua estranxeira (Facultade de Ciencias da Educación da Universidade de Santiago de Compostela). Nos gustaría subrayar que las actividades que presentamos aquí son en su totalidad originales de los estudiantes de la promoción mencionada; ellos eligieron las lenguas y seleccionaron los aspectos presentados, así como las tareas propuestas para cada una y, en conjunto, el diseño de los materiales. Para nosotras estos trabajos tienen, entre otras virtudes, la de poner en práctica elementos aprendidos en otras disciplinas en su aplicación, más o menos acertada, a una tarea propuesta desde el ámbito lingüístico. 


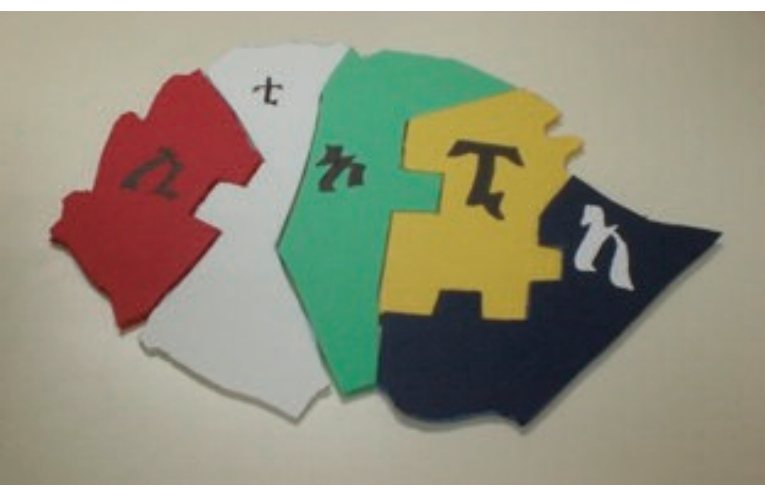

Figura 1. Puzle en amárico (Etiopía).

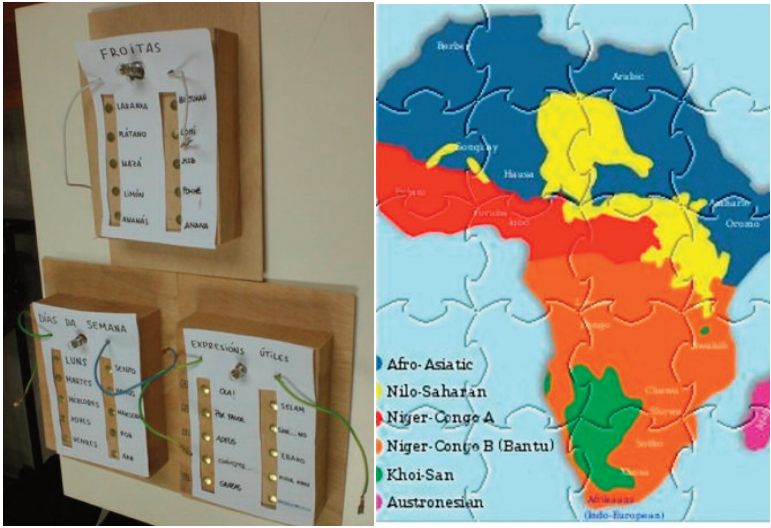

Figura 2. Amárico (frutas, días de la semana, enunciados básicos)

Figura 3. Familias lingüísticas (África)

puesto en un panel (Figura 1).

Otra actividad propuesta consiste en unir vocabulario básico del gallego con su correspondencia en amárico, mediante el contacto de dos cables; cuando la asociación se ha hecho con la palabra correcta, se ilumina la bombilla (Figura 2). Esta actividad se podría realizar, tal como ellos sugirieron, en colaboración con el departamento de Ciencias Naturales.

Para la lengua volof, los estudiantes proponen la realización de un puzle del continente africano, en el que se obtiene la distribución geográfica de las familias lingüísticas de África (Figura 3).

No faltaron actividades en las que se incorporaron las nuevas tecnologías, ya lo hemos comentado. Como ejemplo, mencionamos alguna de las propuestas para la lengua maya, elaboradas con el programa JClic, en que se propone emparejar una fotografía de un animal con su nombre en maya. En el transcurso de la actividad una serie de mensajes va apareciendo según el jugador acierte o no, con dispositivos para contabilizar el tiempo y los errores (Figuras 4 y 5 ).

Sobre el gaélico, la primera actividad consistió en la proyección del documental Yu ming is ainm dom $^{8}$. En este cortometraje se recoge la experiencia vivida por un joven chino que, decidido a cambiar de estilo de vida, planea una huida a Irlanda y aprende la lengua del país: el gaélico. Al llegar a su destino descubre que la realidad lingüística irlandesa es muy diferente de lo que imaginaba, pues el inglés es el idioma predominante. Tras el visionado del documental, se

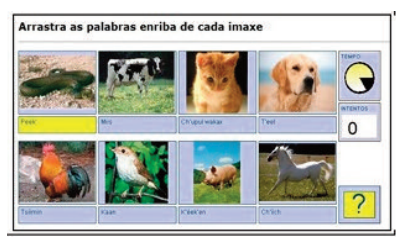

Figura 4. Nombres de animales en maya

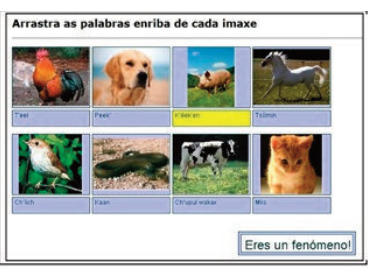

Figura 5. Nombres de animales

en maya. Mensaje tras un acierto

\section{O’Donnell é...}

\section{A) O nome dunha rúa de Barcelona}

\section{B) Significa en irlandés "neto de Donnell".}

\section{C) $\mathrm{O}$ autor dunha famosa canción irlandesa.}

Figura 6. Pregunta 4 del Quiz sobre el gaélico

propone una segunda actividad que consiste en un Quiz $^{9}$ interactivo titulado Canto sabes de gaélico. El cuestionario, realizado con el programa PowerPoint, consta de seis preguntas relacionadas con la cultura irlandesa, con tres posibles respuestas, de entre las cuales el participante debe distinguir la correcta para poder avanzar ${ }^{10}$.

\section{Conclusiones}

Nuestra intención al exponer este conjunto de actividades ha tenido por objeto, en primer lugar, contribuir a la reflexión, dentro del ámbito universitario, sobre la formación de los futuros maestros en lo que afecta a sus actitudes hacia la realidad plurilingüe y multicultural de las aulas. En qué medida esta actitud pueda condicionar el mayor éxito o fracaso en la adquisición de competencias lingüísticas en el alumnado de Primaria y, sobre todo, en qué medida contribuya a fomentar una disposición favorable, libre de prejuicios en el aula, hacia la diversidad lingüística y cultural, son las cuestiones que consideramos de mayor relevancia.

A nuestro modo de ver, es responsabilidad del diseño de los nuevos títulos de Grado de Maestro y del Máster de Profesorado de Secundaria no dejar de lado estos aspectos esenciales en torno a los aprendizajes lingüísticos. En la revisión de Brotons Rico (2006) sobre los créditos previstos en las nuevas titulaciones de grado y máster para el ámbito de enseñanza y aprendizaje de lenguas resultaban unos datos paupérrimos:

"De los 180 créditos de formación académica básica (unas 4.500 horas entre docencia en aulas, tutorizaciones, actividades prácticas, estudio, elaboración de tra-

\footnotetext{
${ }^{8}$ Cortometraje dirigido por Daniel O'Hara en 2003 (duración 13 minutos). Enlace para acceder: http://www.youtube.com/watch?v=qA0a62wmd1A

${ }^{9}$ La palabra quiz, de origen irlandés, hace referencia a un cuestionario o batería de preguntas.

${ }^{10}$ En los anexos incluimos el Quiz completo (A1) y un vídeo con vocabulario del bretón (A2).
} 
bajos, prácticas en centros educativos, etc.) sólo se contemplan 20 créditos en Educación Infantil y 22 en Educación Primaria para "Enseñanza y aprendizaje de las lenguas", es decir, un poco más del 10\%. Poco, muy poco, para dominar adecuadamente las dos lenguas oficiales, básicamente una extranjera, y adquirir los fundamentos psicopedagógicos y didácticos para responder con garantías de éxito a los retos que plantean los programas educativos plurilingües".

Hoy ya están en marcha las nuevas titulaciones y creemos que, a pesar de la ampliación en créditos respecto a la Diplomatura, los resultados de la planificación del currículo del Grado de Maestro no son muy halagüeños. Las asignaturas de áreas lingüísticas se han visto reducidas drásticamente, en contra de lo que la realidad multilingüe y multicultural de la escuela, las voces de los expertos y el sentido común demandaban.

En lo que se refiere a la programación conjunta que hemos llevado a cabo, nuestra valoración es muy positiva, pues consideramos que los objetivos se han cumplido sobradamente, con una respuesta entusiasta de los estudiantes que ha superado con creces nuestras expectativas. Ha primado una metodología activa, con tareas auténticas y gran implicación del grupo, consciente de la importancia de su participación en el trabajo colaborativo.

Pero sobre todo queremos hacer hincapié en el hecho de que las lenguas sobre las que los grupos de estudiantes han trabajado no se limitan al ámbito peninsular ni europeo, ni se trata de vehículos lingüísticos considerados hoy de prestigio o relevancia social. A nuestro modo de ver este curso ha supuesto para el alumnado la adopción de una nueva perspectiva, más sensible hacia aspectos sociolingüísticos, más consciente de la diversidad lingüística y cultural, y no exclusivamente centrada en la didáctica de lenguas extranjeras.

Para terminar, destacamos algunos comentarios del alumnado en la evaluación incorporada a los diarios de clase, en concreto algunas de sus reflexiones en torno al aprendizaje de lenguas y la diversidad lingüística y cultural:

"Dada la sociedad diversa en la que vivimos, debemos cuidar que todas las lenguas, aún más aquellas a las que etiquetamos de minoritarias, sean respectadas y conservadas. De lo contrario, no sólo perderíamos una lengua, sino una parte de nuestra cultura universal. En los últimos 15 años han desaparecido alrededor de 2000 lenguas. ¿Qué vamos a hacer para que lenguas como el maya no desaparezcan en los 15 siguientes?

Con este trabajo nos hemos dado cuenta de que la mayoría de la gente en nuestro país se interesa únicamente por las lenguas indoeuropeas, ya que es la familia a la que pertenecen nuestras lenguas, y es igualmente importante conocer lenguas de otras familias lingüísticas. No debemos guiarnos por el número de hablantes a la hora de aprender un idioma sino por el interés que podamos tener por su cultura o simplemente para aprender nuevas lenguas.

Creemos que en las aulas existe una necesidad incipiente de conocer idiomas, pero no reglas y normas, sino culturas y formas de expresión. Para esto es indispensable crear material sobre las lenguas y fomentar el interés y la concienciación en los alumnos para que lleguen a ser conscientes del patrimonio que suponen las lenguas, independientemente de su número de hablantes."

\section{Referencias bibliográficas}

AA VV (2005). Conclusiones del Encuentro "La Didáctica de la Lengua y la Literatura: Presente y futuro", Gibralfaro. Revista de Creación Literaria y Humanidades, Año IV, $\mathrm{n}^{0}$ 28, marzo de 2005,

http://www.gibralfaro.uma.es/educacion/pag_1099.h tm Fecha de consulta, 29.01.2011.

Bernaus, Mercè (2004). Un nuevo paradigma en didáctica de la lengua. Glosas didácticas, $\mathrm{n}^{0} 1$, pp. 3-13. Accesible en http://www.um.es/glosasdidacticas/doces/o2bernaus.pdf Fecha de consulta, 12.12.2011.

Brotons Rico, Vicent (2006). Enseñantes para una sociedad plurilingüe. Notas y reflexiones para el debate sobre las nuevas titulaciones - grado y máster- educativas. Avances en Supervisión Educativa, $\mathrm{n}^{0}$ 3, mayo de 2006, http://adide.org/revista/index.php?option=com_cont ent\&task=view\&id=37\&Itemid=30 Fecha de consulta, 10.10.2011.

Cassany, Daniel (Coord.) (2006). El Portfolio Europeo de las lenguas y sus aplicaciones en el aula. Madrid: Ministerio de Educación y Ciencia. Instituto Superior de Formación del Profesorado.

Coelho, Elisabeth (2008). Elisabeth Coelho, experta educativa, ve necesario formar al docente en el multiculturalismo. Noticia de EFE 27.02.2008), http://www.aulaintercultural.org/printbrev.php3?id breve=1370; http://www.multilingualclassrooms.org/ Fecha de consulta, 10.10.2011.

Consejo de Europa (2001). Common European Framework for Languages: Learning, Teaching, Assessment. Council for Cultural Cooperation. Education Comitee. Language Policy Division. Estrasburgo.

Grupo Eleuterio Quintanilla (2006). Lengua y diversidad cultural. Actividades para el aula. Madrid: Talasa ediciones.

Lomas, Carlos (2011). El poder de las palabras y las palabras del poder. Enseñanza del lenguaje y educación democrática. Textos. Didáctica de la lengua y de la Literatura, $\mathrm{n}^{0}$ 58, pp. 9-21.

Mas Álvarez, Inmaculada; Zas Varela, Luz (2009). Tomando conciencia da diversidade lingüística. En María Teresa Díaz García, Inmaculada Mas Álvarez y Luz Zas Varela (Coords.). Diversidade lingüística e cultural no ensino de linguas. Santa Comba: TresCtres, pp. 83-118.

Moreno Cabrera, Juan Carlos (2000). La dignidad e igualdad de las lenguas: Crítica de la discriminación lingüística. Madrid: Alianza Editorial.

Tinsley, Teresa (2003). Language education in a multiethnic Society. En Facing the future: Language educators across Europe. Estrasburgo: Ediciones del Consejo de Europa, pp. 39-49.

Última palabra. Dosier documental (World Congress on Language Policies, Barcelona, 16-20 abril de 2002), http://www.linguapax.org/congres/taller/ultimapalabra.html Fecha de consulta, 10.10.2011.

Última palabra (2001). Documental de 52 minutos de duración, dirigido por Grau Serra Espriu. Producido por Milana Bonita y Grau Serra, en colaboración con el Centro de Capacitación Cinematográfica de México D.F. Fragmento de 5':

http://www.youtube.com/watch?v=zsd_nV18nP8 
Anexo 1. Quiz Completo

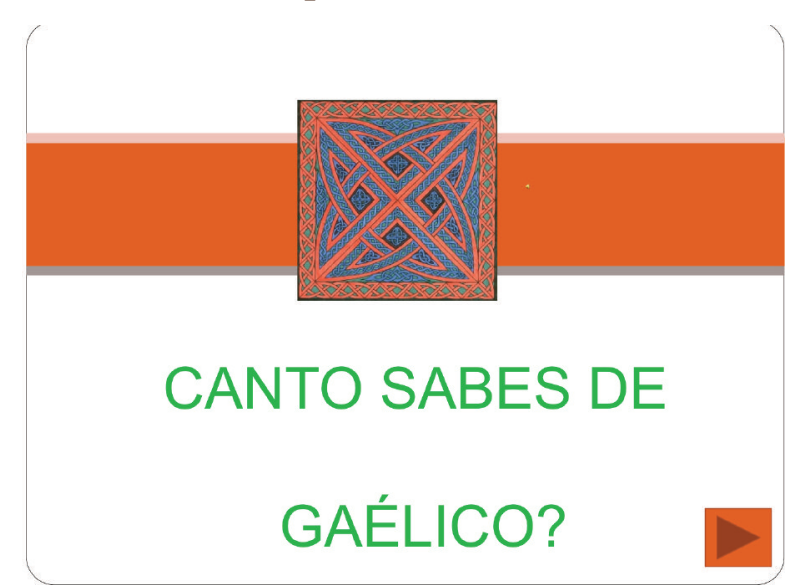

1.Un quiz é...

A) Un postre típico de Irlanda feito con licor.

B) Unha canción típica irlandesa.

C) Unha pregunta, un interrogatorio, un test...

\section{Dubh Linn é...}

A) O antigo nome da capital de Irlanda.

B) Un acantilado da costa irlandesa.

C) Un grupo de música irlandesa.

\section{Mac Arthur é...}

A) Un coñecido militar irlandés.

B) Significa en irlandés "fillo de Arthur".

C) Unha marca de cervexa que compite con Guinness.

\section{O' Donnell é...}

A) O nome dunha rúa de Barcelona.

B) Significa en irlandés "neto de Donnell".

C) O autor dunha famosa canción irlandesa.

5. Se ao final dunha carta en gaélico, envías o teu "grá" a alguén, que recibe esa persoa?

A) Un atento saúdo.

B) Amor.

C) Recordos para toda a familia.

\section{Se falamos de Eamon, Connor e Padraig, estamos a falar de...}

A) Os tres nomes para nenos máis populares de Irlanda.

B) Tres cidades do interior de Irlanda.

C) Os últimos tres presidentes da República de Irlanda.

\section{Pénsao de novo e volve intentalo!!}

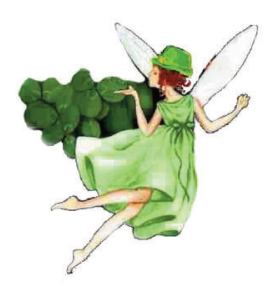




\section{Moi ben, sabes máis gaélico do que pensabas!!!

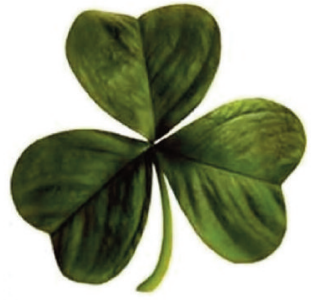

\section{RESULTADOS}

- 5 ou máis acertos: Es un experto en gaélico! Recibirás un diploma que acredita a túa condición de embaixador do gaélico.

- 3 ou 4 acertos: Noraboa, os teus coñecementos de gaélico son notábeis. Se queres mellorar, Irlanda espérate cos brazos abertos!

- Menos de 3 acertos: Parabéns polo esforzo! 0 gaélico non é o teu... Pero Irlanda está a agardar por ti para emprender a aventura de coñecer a súa lingua. Ánimo!

LECCIÓNS DE GAÉLICO:

AGORA QUE SABES ALGO DA SÚA

CULTURA, ANIIMASTE A APRENDELO?

E para aqueles que queiran ampliar os seus coñecementos de gaélico, colocamos unha pantalla noutro dos laterais do cubo, a través da cal o visitante poderá acceder a varias leccións básicas de gaélico.

Lección 1

Lección 2

Animate a aprendelo!

\section{Anexo 2. Vídeo con vocabulario del bretón}

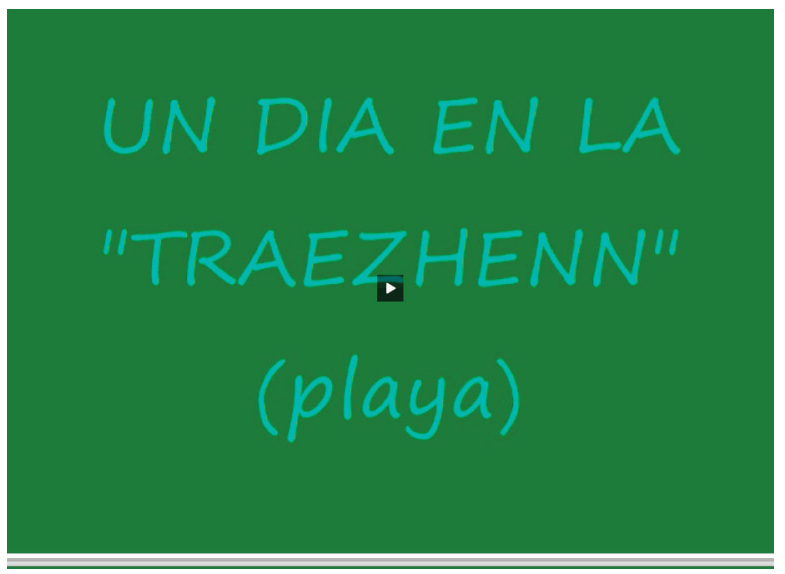

Haga clic sobre el vídeo para reproducirlo.

\section{| Cita recomendada de este artículo}

Mas Álvarez, Inmaculada y Zas Varela, Luz (2011). Diversidad lingüística y educación. @tic. revista d'innovació educativa. (n. 7). URL. Fecha de consulta: $\mathrm{dd} / \mathrm{mm} /$ aaaa. 